NASA/TM-1998-208825
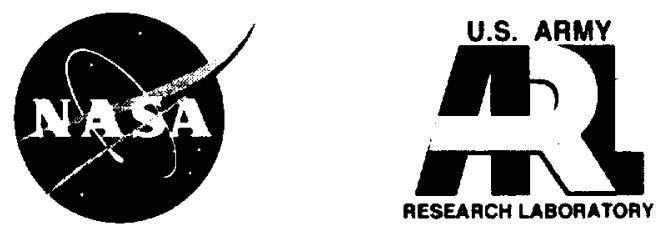

\title{
Model-Based Fault Diagnosis for Turboshaft Engines
}

Michael D. Green and Ahmet Duyar

Florida Atlantic University, Boca Raton, Florida

Jonathan S. Litt

Lewis Research Center, Cleveland, Ohio

Prepared for the Symposium on Fault Detection, Supervision and Safety for Technical Processes - SAFEPROCESS '97

sponsored by the International Federation of Automatic Control Kingston Upon Hull, United Kingdom, August 26-28, 1997

National Aeronautics and

Space Administration

Lewis Research Center 


\section{Acknowledgments}

This work was funded by the Army Research Laboratory's Vehicle Technology Center and NASA Lewis Research Center under grant NAG3-1198. The authors wish to express their gratitude to Captain Anne Daugherty of the Vehicle Technology Center and Angelo Moretti of the ATCOM Maintenance Directorate for their help in clarifying some of the T700 maintenance procedures.

Available from

NASA Center for Aerospace Information 7121 Standard Drive Hanover, MD 21076

Price Code: A03
National Technical Information Service 5285 Port Royal Road Springfield, VA 22100

Price Code: A03 


\title{
MODEL-BASED FAULT DIAGNOSIS FOR TURBOSHAFT ENGINES
}

\author{
Michael D. Green', Ahmet Duyar', and Jonathan S. Litt ${ }^{2}$ \\ 'Department of Mechanical Engineering \\ Florida Atlantic University, Boca Raton, FL 3343I \\ ${ }^{2}$ Vehicle Technology Center \\ U.S. Army Research Laboratory \\ Lewis Research Center, Cleveland, Ohio 44/35
}

\begin{abstract}
Tests are described which, when used to augment the existing periodic maintenance and pre-flight checks of T700 engines, can greatly improve the chances of uncovering a problem compared to the current practice. These test signals can be used to expose and differentiate between faults in various components by comparing the responses of particular engine variables to the expected. The responses can be processed on-line in a variety of ways which have been shown to reveal and identify faults. The combination of specific test signals and on-line processing methods provides an $a d$ hoc approach to the isolation of faults which might not otherwise be detected during pre-flight checkout.
\end{abstract}

Keywords: Fault detection, Fault diagnosis, Engine, Helicopter, Diagnostic tests

\section{INTRODUCTION}

This report presents the research work on the design of a model-based fault detection and diagnosis (FDD) system for use in turboshaft engine maintenance. The FDD system detects component malfunctions (faults) by monitoring engine output during maintenance testing. This work focuses on components related to fuel control actuation to demonstrate the applicability of the method. A previous study (Litt, et al., 1995) presented a related scheme for detection of sensor faults.

Current engine maintenance procedures at the Aviation Unit Maintenance (AVUM) and Aviation Intermediate Maintenance (AVIM) levels are described in T700 (1981). There are several on-line and pre-flight checks which are performed currently on T700 engines (figure 1) in Blackhawk and Apache helicopters. These include the Health Indicator Test (HIT) check which is performed at flight idle and compares exhaust temperature to power level to make sure it is within range. On-line cockpit instrumentation indicates engine chips (metallic particles in the oil) and oil temperature and pressure limits. These provide information about the existence of a problem without determining the cause. An artificial intelligence-based diagnostic system (Aerospace Engineering, 1995) has been tried in order to get more information about individual components, but it only gives an indication of the likely source of the problem, if one is detected, and this often requires several steps after the testing is completed.

On the other hand, model-based fault detection methods compare the system's output to that of a model running simultaneously. Any difference beyond a threshold value signifies that a fault has occurred. The present work evaluates the faults using the approach developed and implemented by Litt, et al. (1995) and by Duyar, et al. (1994). The experimental modeling technique developed by Duyar, et al. (1995) is used to obtain the state space diagnostic model, i.e., the model used to determine faults. Test input signals for diagnosis purposes to be applied during maintenance of the engine have been explored and the most suitable chosen.

The model of the normal process developed by Duyar, $e t$ al. (1995) did not include the dynamics of fuel control actuation (the hydromechanical unit, HMU). The HMU output fuel flow rate was used as input to the model rather than the command signals from the electrical control unit (ECU) and the collective (figure 2). In the work reported here, the ECU and collective 


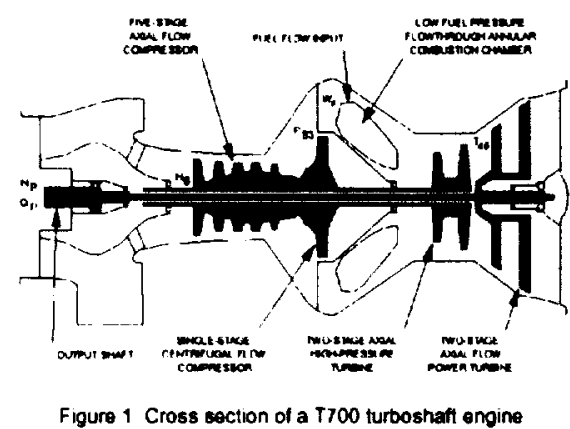

command signals were used as inputs to an open-loop block diagram of a $\mathrm{T} 700$ turboshaft helicopter engine, which implicitly incorporates the HMU dynamics, thus converting the HMU's fuel flow to an output (figure 2). Further, in the present work the block diagram was derived such that the engine is separated from the rotor system. This strategy makes it possible for the resulting open-loop model to be used not only for FDD, but also for control design and system simulation when linked with an appropriate rotor system model.

The trouble-shooting procedures of Litt, et al., (1995) were studied together with information on the components involved found in Ballin (1988) and the T700 Training Manual (Prescott and Morris, 1987) to identify potential faults to be considered. Two potential actuator faults listed were selected to illustrate the method: an increase in friction in the torque motor and a clogging fuel metering valve. Two additional faults, which are outside the actuation system, were also modeled: degradation of combustion efficiency in the combustor and increase in the ECU reset rate.

The Model-Based Fault Detection (MBFD) technique will not only indicate which component is malfunctioning but indicate which fault is occurring and estimate the magnitude of the fault (Litt, et al., 1995). It can be used both during the pre-flight HIT check and, if desired, during flight to indicate potential faults which should be investigated before there is an actual failure.

This report has four parts: diagnostic model development, simulation of faults, results, and conclusions.

\section{DIAGNOSTIC MODEL DEVELOPMENT}

The objective of this part of the study was to develop experimental, open-loop, state space, diagnostic models of the T700 turboshaft engine for use in the FDD system design. Figure 1 shows a schematic diagram of the T700 turboshaft engine. An open-loop model of the T700 engine has been developed consisting of the $\mathrm{HMU}$, gas generator, and power turbine as a unit.

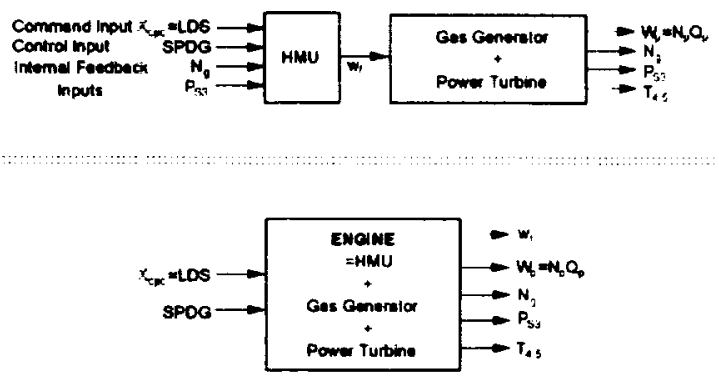

Figure 2. T700 Macroscopic Open Loop Block Diagrams (HMU is represented by simplified model)

The description of the operation of the engine and the engine variables can be found in Duyar, et al. (1995), which derived an experimental, open-loop model of the T700 gas generator and power turbine as a unit. The actuation mechanism, i.e., the HMU and associated fuel system components ${ }^{1}$ were not, however, included. Duyar, et al. (1995) used input fuel flow variations to develop the experimental model of the gas generator and the power turbine. In the work reported here, on the other hand, the collective and ECU command signals were used as input to the HMU, thus restricting fuel flow variations to those which the HMU could physically produce. This yields an improvement in the gas generator and power turbine model, since the model parameters are fit to a more realistic set of input variations.

Prior to actually generating the experimental state space models, open-loop block diagrams were developed such that the engine is separated from the rotor system. This approach makes it possible for the open-loop models to be used, not only for fault detection and diagnosis system design, but also for control design purposes and for simulation studies to determine the effect of using different rotor systems. The block liagrams were developed by considering the physical processes occurring in the components, the constraints imposed by the available tool for generation of the experimental data, i.e., the simulation developed by Ballin (1988), and the variables that are affected by faults. The simplified open-loop block diagrams developed are shown in figure 2. The closed-loop diagram is presented in figure 3 . The first step in the developme it of these block diagrams was to construct a major functions/components diagram using the information in Litt, et al. (1995), Ballin (1988), and Prescott and Morris (1987).

Ir this work the various parts of the fuel regulating system associated with the HMU (F uel Boost Pump, Pressurizing and Overspeed Unit (POU), and Fuel Injectors) are referred to collectively as the HMU. 


$$
x(n+1)-A x(n)+B u(n)
$$

$$
y(n) \cdot C x(n)
$$

where $\mathbf{x}, \mathbf{u}$, and $\mathbf{y}$ are the $m \times 1$ state, the $p \times 1$ input, and the $q \times 1$ output vectors, respectively. A, B, C are the known nominal matrices of the system with appropriate dimensions. The process noise, measurement noise, and the modeling errors due to uncertainties in the parameters are not included for mathematical simplicity. It is assumed that the system is in $\alpha$ canonical form (Litt, et al., 1995).

Figure 3. T700 Closed-Loop Block Diagram (ECU wnd HMU wo reoremented by implified modeto)

Emphasis was placed on identification of the fuel control-related components which are replaced during AVUM and AVIM level trouble-shooting procedures. The block diagrams shown in figure 2 and figure 3 were obtained by simplifying this major functions/components diagram, while ensuring that the significant functionalities were maintained.

Careful evaluation of the physical processes in turbine engines shows that, for a stand-alone model of the engine (one which can be used with different rotor systems), the essential output of the engine is power, $W_{p}$. Under ideal conditions, the power is a function of only the conditions produced by the gas generator at the power turbine entrance. Power turbine power is fed to the load-the rotor system of the specific aircraft. This power is the product of the power turbine torque, $Q_{p}$, and the power turbine speed, $N_{p}$, which are both measured quantities. The load dynamics determine the split of the power between speed and torque at any particular time.

Additional outputs of the engine which show the effects of the faults are the fuel flow rate, $w_{\mathrm{f}}$ the gas generator speed, $\mathrm{N}_{\mathrm{g}}$, power turbine inlet temperature, $\mathrm{T}_{45}$, and the compressor final stage pressure, $\mathrm{P}_{53}$. The inputs to the $\mathrm{HMU} /$ engine system are the collective pitch angle, $\mathrm{X}_{\mathrm{cpc}}$, and the trim signal from the electrical control unit, SPDG. The power available spindle angle, PAS, and the inlet air temperature, $T_{2}$, are assumed to be constant in this study and therefore are not included as inputs. Under normal operation of the engine PAS is regularly kept at a constant angle. Therefore the model developed in this study is restricted to normal flight conditions or testing at these conditions.

It is assumed that the nonlinear open-loop dynamics of the engine can be normalized and linearized about a nominal operating condition and can be expressed as a discrete-time linear system described by the following state equations
The procedure explained in Duyar, et al. (1995) was followed to obtain the experimental model. A threelevel pseudo random sequence was used for the $\mathrm{ECU}$ trim signal input. A modified version of this three level signal, where changes from one level to another occur through a ramp function rather than a step function, was used for the collective input. This modification is warranted because the collective input is a mechanical input and cannot change instantaneously. Figure 4 shows these input signals used to identify the open-loop engine model.

Most of the interaction between the rotor, drive train, and engine takes place at or below the main rotor frequency of about $300 \mathrm{rpm}$. Thus it is important that the simulation be accurate in the range below $5 \mathrm{~Hz}$. Therefore a clock time of 2 seconds and a length of 26 was used with the three level sequences. Sampling time was selected to be 0.1 second. This corresponds to a maximum frequency of $31.4 \mathrm{rad} / \mathrm{sec}(5 \mathrm{~Hz})$, a minimum frequency of $0.24 \mathrm{rad} / \mathrm{sec}(0.04 \mathrm{~Hz})$, and a signal duration of $26 \mathrm{sec}$.

For the purposes of this study the $\mathbf{A}, \mathbf{B}$, and $\mathbf{C}$ matrices were obtained for the single power level of approximately $100 \%$. Table 1 presents the resultant open-loop state space engine model.

\section{SIMULATION OF FAULTS}

It is important to understand which components realistically may fail and how these failures may be reflected in observable engine outputs in order to construct a meaningful diagnostic model. To this end the Aviation Unit and Intermediate Maintenance Manual (T700, 1981) for the T700 helicopter engine was reviewed to identify faults dealt with at the AVUM and AVIM levels. The trouble-shooting procedures in the manual were studied together with information on the components involved found in Prescott and Morris (1987) and Ballin (1988) to identify potential faults to be considered. These faults are presented in Table 2 . 
Table 1. Open-Loop State Space Engine Model at $100 \% \mathrm{~N}_{\mathrm{B}}$

\begin{tabular}{|c|c|c|c|c|c|c|c|c|}
\hline$x$ & \multicolumn{5}{|c|}{$\mathbf{A}$} & \multicolumn{2}{|c|}{ B } & $\mathbf{u}$ \\
\hline $\mathrm{N}_{\mathrm{B}}^{*}$ & 1.1522 & 0.0042 & 0.0975 & -0.1043 & -0.0028 & -0.0034 & 0.0066 & SPDG $^{*}$ \\
\hline$W_{p}{ }^{*}$ & 1.7486 & 0.9596 & 0.6840 & -0.7971 & -0.1771 & -0.0559 & 0.1228 & $X_{\mathrm{cpc}}{ }^{*}$ \\
\hline$T_{45} *$ & 0.7718 & 0.4339 & 1.0821 & -0.8655 & -0.3867 & -0.0994 & 0.1433 & \\
\hline $\mathrm{P}_{\mathrm{S} 3}{ }^{*}$ & 1.1269 & -0.0271 & 0.4144 & 0.4985 & -0.0177 & -0.0137 & 0.0325 & \\
\hline$w_{f}^{*}$ & 2.9536 & 1.1513 & 0.4429 & -2.6096 & -0.0402 & -0.2603 & 0.3738 & \\
\hline $\mathbf{y}$ & \multicolumn{5}{|c|}{ C } & \multirow{6}{*}{\multicolumn{3}{|c|}{$\begin{array}{l}\text { The asterisk, }{ }^{*} \text {, indicates that the elements } \\
\text { of the } u, \mathbf{x} \text {, and } \mathbf{y} \text { vectors are normalized } \\
\text { perturbations from the initial, steady-state } \\
\text { values of the indicated parameters: } \\
\qquad \mathrm{z}^{*}=\left(\mathrm{z}-\mathrm{z}_{0}\right) / \mathrm{z}_{0} \text {. }\end{array}$}} \\
\hline $\mathrm{N}_{\mathrm{g}}^{*}$ & 1.0 & 0.0 & 0.0 & 0.0 & 0.0 & & & \\
\hline$W_{p}^{*}$ & 0.0 & 1.0 & 0.0 & 0.0 & 0.0 & & & \\
\hline$T_{45} *$ & 0.0 & 0.0 & 1.0 & 0.0 & 0.0 & & & \\
\hline$P_{53}{ }^{*}$ & 0.0 & 0.0 & 0.0 & 1.0 & 0.0 & & & \\
\hline$w_{r}^{*}$ & 0.0 & 0.0 & 0.0 & 0.0 & 1.0 & & & \\
\hline
\end{tabular}

Two of the potential actuator faults listed in Table 2 were selected to illustrate the method. One was chosen to be essentially at an "entrance" to the HMU. The other is essentially at the "exit." For the entrance, increasing friction in the torque motor is emulated by an increasing value of the torque motor lag. (The appendix details the basis for modeling this fault.) For the exit, a clogging fuel metering valve is emulated by multiplying the flow through the valve by a factor less than one.

Two additional faults, which are outside the actuation system, have also been modeled: degradation of combustion efficiency in the combustor and increase in the ECU reset rate.

\section{RESULTS}

Several measures for detection of faults were explored. These included using the instantaneous difference in peak values between faulted and nominal outputs, and the integral of the difference between faulted and nominal outputs. Likewise a number of different input signals were explored - periodic signals such as that for $\mathrm{X}_{\mathrm{cpc}}$ in Figure 4, and as in Duyar, et al., (1995) and Ballin (1988), limited ramps and steps. (For the closed loop engine-which is what would be actually tested-the only input available is $\mathrm{X}_{\mathrm{cpc}}$. The values of SPDG used for input to the state space model were calculated by Ballin's model using the given input sequence for $\mathrm{X}_{\mathrm{cpc}}$.)
The step or ramp input in $X_{c p c}$, coupled with the integral of the difference between faulted and nominal output, gave satisfactory results. The other fault detection measures failed to sufficiently distinguish between faulted and nominal conditions. Since a true step input is physically impossible, a limited ramp input is recommended. The recommended input uses an increase in $X_{c p}$ in a five-second ramp from the initial, steady-state value to the same maximum value that is used for establishing the model (figure 4), then remains constant at that value.

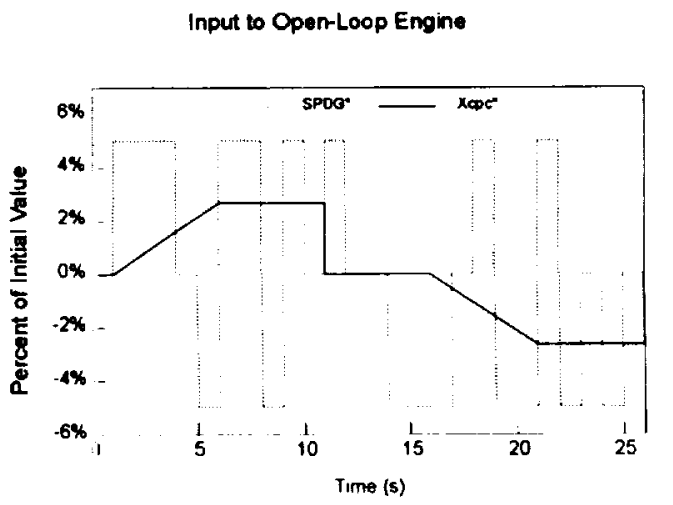

Figure 4. input signals used to identify open-loop engine model 


\begin{tabular}{|c|c|c|}
\hline $\begin{array}{l}\text { Component } \\
\text { Actuators }\end{array}$ & Sub-Component & Fault \\
\hline \multirow{14}{*}{$\begin{array}{l}\text { "HMU" } \\
\text { (For the purposes of this study the } \\
\text { scope of the HMU has been extended } \\
\text { beyond that of the physical } \\
\text { component to create a functional } \\
\text { HMU which includes the physical } \\
\text { HMU, the fuel injectors, POU, and } \\
\text { fuel boost pump. These components } \\
\text { all work together to control fuel } \\
\text { flow.) }\end{array}$} & \multirow{3}{*}{ torque motor } & increased rotational friction \\
\hline & & decreased maximum travel \\
\hline & & increased deadband \\
\hline & \multirow{3}{*}{ metering valve } & clogging \\
\hline & & increased wear \\
\hline & & increased friction \\
\hline & \multirow{2}{*}{ vane pump } & increased tip leakage \\
\hline & & sticking vanes \\
\hline & \multirow{2}{*}{$N_{B}$ spool } & increased hysteresis \\
\hline & & increased friction \\
\hline & Fuel injectors & clogging \\
\hline & POU & sticking valves \\
\hline & \multirow{2}{*}{ Fuel boost pump } & clogging \\
\hline & & leaking \\
\hline \multicolumn{3}{|l|}{ Sensors } \\
\hline \multirow{2}{*}{$\begin{array}{l}\mathbf{P}_{\mathrm{S} 3} \text { Hose and Tube Assembly }+\mathbf{P}_{\mathrm{S} 3} \\
\text { Sensor }\end{array}$} & & leaking or loose hose \\
\hline & & faulty sensor \\
\hline Power Turbine Speed Sensor & & faulty sensor \\
\hline Power Turbine Torque Sensor & & faulty sensor \\
\hline Thermocouple Assembly & & faulty sensor \\
\hline \multirow{2}{*}{ Yellow Electrical Cable } & & broken wires \\
\hline & & loose or corroded connections \\
\hline
\end{tabular}

Figure 5 shows the integrated differences between the fuel flow predicted by the state space model and those calculated by Ballin's model for a five-second ramp beginning one second into the run. Included are curves for the no-fault condition and for faults in the HMU, ECU, and combustor:

- $100 \%$ increase in the reset rate for the ECU PI controller

- $10 \%$ decrease in efficiency in the combustor

- $10 \%$ increase in HMU metering valve clogging

- $20 \%$ increase in HMU metering valve clogging
As can be seen, the slopes for increases in metering valve clogging are steeper than the no fault slope. This effect increases with increases in percent clogging. This method, therefore, yields an effective means of detecting a fault.

The difficulty lies in effectively isolating the source of the fault. Figure 5 shows a negative slope for the case where combustion efficiency has degraded, while a clogged metering valve produces a positive slope. This provides an encouraging indication that this approach can be used to help in the isolation of HMU and combustor faults. However, applying this technique 


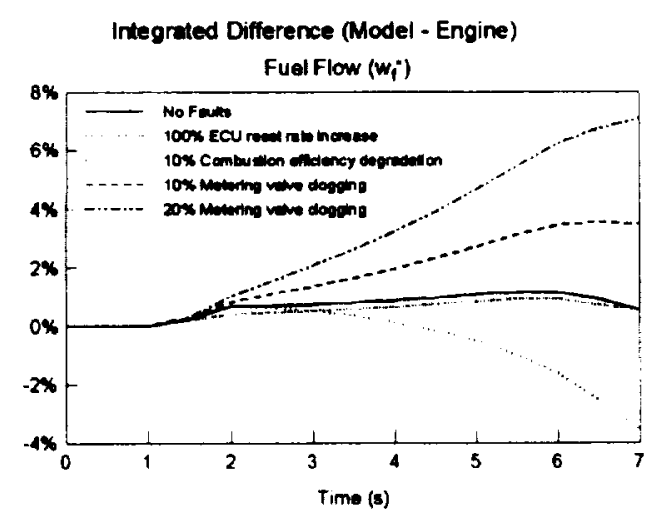

Figure 5. Integrated fuel flow difference

when the fault involved an increase in the ECU reset rate yielded a slope similar to that of the no fault case. Thus, although this method may be able to distinguish the HMU fault (metering valve clogging) from a combustor fault, without additional information it does not distinguish a faulty ECU.

\section{CONCLUSIONS}

A method for detection of faults originating in the actuation system of a T700 turboshaft engine has been developed and demonstrated. One can design input signals to enhance the effect of the fault. Injection of faults resulted in clearly detectable differences between actual system outputs and those calculated by the nominal model for realistic test input. A complete set of criteria can be generated to assist in isolating malfunctioning components during pre-flight engine maintenance by coupling the approach laid out here with that of Litt, et al. (1995) for sensor faults. Diagnostic equipment which uses this method would help focus maintenance procedures on the faulty component. This could greatly shorten the present trial and error methods for malfunction elimination.

At least three areas need to be pursued further: 1) The ECU fault could not be detected using the methods demonstrated. An ECU model might need to be incorporated into the diagnostic model in order to accomplish this. 2) The open-loop state space engine and HMU models need to be obtained for other power levels (in addition to that of $100 \%$ presented in Table 1, flight idle for instance). Together with this, techniques for joining the linear state space models at the various discrete power levels to obtain an effectively non-linear model need to be explored. 3) The approach laid out here should be integrated with that of Litt, et al. (1995) for sensor faults to generate a complete set of criteria to assist in isolating malfunctioning components.

6. APPENDIX: Modeling Torque Motor Faults The torque motor is modeled in Ballin (1988) by a simple integrator, fed by filtered and limited signals. This is consistent with the discussion of servomotors on pp. 96 ff. of Ogata (1970). Ogata shows that both two- phase $\mathrm{AC}$ and armature-controlled DC servomotors are approximalely integrators, i.e. they reduce to the form $\mathrm{K}_{\mathrm{m}} / \mathrm{s}$. (Anc ther type, field-controlled DC servomotors, has a mucl more complex transfer function.) For the $\mathrm{AC}$ motor:

$$
K_{m}=K_{c} /\left(f+K_{n}\right)
$$

where

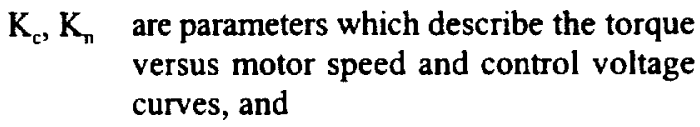

f is the viscous friction coefficient of the motor and load referred to the motor shaft, i.e. the product of $f$ and the angular speed of the motor shaft is the total torque due to friction in the motor and load.

For the fied-controlled DC motor:

$$
\begin{aligned}
K_{m} & =K /\left(R_{a} f+K_{b}\right) \\
& =\left(K / R_{\mathfrak{a}}\right) /\left[f+\left(K_{b} / R_{\jmath}\right)\right]
\end{aligned}
$$

where

$\mathrm{K}$ is the slope of the torque versus armature current line,

$R_{a}$ is the armature winding resistance,

f is the viscous friction coefficient of the motor and load referred to the motor shaft, i.e. the product of $f$ and the angular speed of the motor shaft is the total torque due to friction in the motor and load, and

$\mathrm{K}_{\mathrm{b}} \quad$ is a back emf constant-the slope of the voltage induced in the armature by rotation versus the angular velocity.

Thus both servomotor types have transfer functions of the form $K_{m}$ /s with $K_{m}=K_{1} /\left(f+K_{2}\right)$, where $f$ is the viscous friction coefficient and $K_{1}$ and $K_{2}$ relate to motor elertrical characteristics. In Ballin's program, $\mathrm{K}_{\mathrm{m}}$ is the factor TMGN, which has the value 0.0159 in $/ \mathrm{ma} \mathrm{sec}$.

Let us as:ume that mechanical degradation is more likely than electrical degradation and that this takes the form of ar: increase in $\mathrm{f}$ :

$$
f=f_{0}(1+d / 100)
$$

where $f_{0}$ is the nominal value of $f$ (corresponding to TMGN $=$ J.0159) and $d$ is the percent increase in $f$. 
Then

$$
\begin{aligned}
\text { TMGN }= & \mathrm{K}_{1} /\left[\mathrm{f}_{0}(1+\mathrm{d} / 100)+\mathrm{K}_{2}\right] \\
= & \operatorname{TMGN}_{0}\left(\mathrm{f}_{0}+\mathrm{K}_{2}\right) /\left[\mathrm{f}_{0}(1+\mathrm{d} / 100)+\mathrm{K}_{2}\right] \\
= & \operatorname{TMGN}_{0} \\
& \times\left(1+\mathrm{K}_{2} / \mathrm{f}_{0}\right) /\left[(1+\mathrm{d} / 100)+\mathrm{K}_{2} / \mathrm{f}_{0}\right]
\end{aligned}
$$

For $\mathrm{K}_{2} / \mathrm{f}_{0} \ll 1$ :

$$
\mathrm{TMGN}=\mathrm{TMGN}_{0} /(1+\mathrm{d} / 100)
$$

$\left(\mathrm{K}_{2} / \mathrm{f}_{0} \approx 0.03\right.$ in the example Ogata gives in the text. In the problems at the end of the chapter, however, he presents some range of examples including one with $\mathrm{K}_{2} / \mathbf{f}_{0} \approx 2.4$. Viscous friction may or may not, therefore, be a dominant effect in the torque motor. This analysis assumes it is. More detail about the specifics of the design would be necessary in order to be sure this is a valid assumption. It can also be noted that the approach taken here could be used to emulate a degradation in the electrical characteristics of the motor. The interpretation of $d$ would change from percent increase in viscous friction factor to percent change in some electrical characteristic; but the results would remain the same.)

This is implemented in Ballin's program by using

$$
\text { TMGN } \approx \mathrm{TMGN}_{0} / \text { tqMotFricFac }
$$

i.e. tqMotFricFac $=(1+d / 100)$. It is assumed that $d$ is never negative and, therefore, tqMotFricFac is limited to be greater than or equal to one.

Figure A-1 shows the variation in Standard Error Estimate (SEE) with d, the percent increase in friction factor. These results are for the open loop engine (figure 2) using the inputs shown in figure 4 . SEE is the square root of the value obtained by dividing the sum of the squares of the difference between the state space result (which does not include any effect of a change in d) and the output of Ballin's model (with the changed d) by the sum of the squares of the output of Ballin's model. RMS is the root mean squared average of the five outputs.

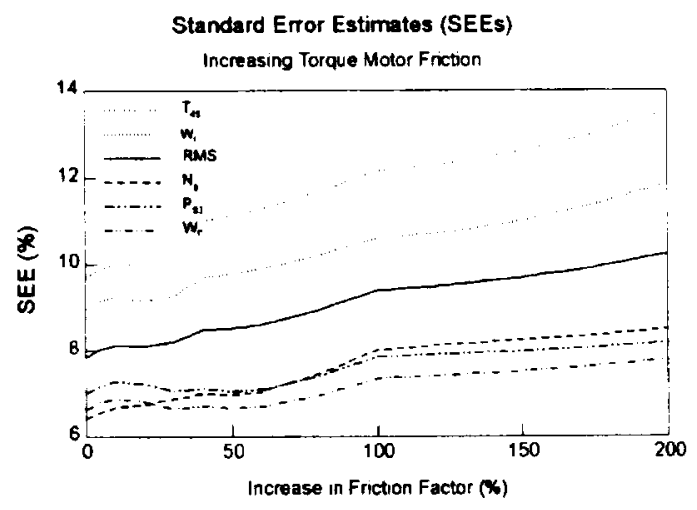

Figure A-1. Effect of Increase in Torque Motor Fnction
It is clear that under ideal conditions, changes in $d$ greater than about $25 \%$ are observable. It is likely, however, that under normal operating conditions, changes in $d$ would need to be at least of the order of $100 \%$ before they are noticed, i.e., the viscous friction would probably have to double, or more, to produce a distinct difference in the SEEs. On the other hand, if changes in $\mathrm{d}$ of less than $100 \%$ produce little observable change in the SEEs, they may also produce little effect on engine performance. It may be that an HMU is not faulty (with respect to the torque motor) unless the viscous friction more than doubles.

\section{ACKNOWLEDGMENT}

This work was funded by the Army Research Laboratory's Vehicle Technology Center and NASA Lewis Research Center under grant NAG-1198. The authors wish to express their gratitude to Captain Anne Daugherty of the Vehicle Technology Center and Angelo Moretti of the ATCOM Maintenance Directorate for their help in clarifying some of the T700 maintenance procedures.

\section{REFERENCES}

Aerospace Engineering (1995). "Artificial Intelligence for Turbine Engine Diagnostics," Aerospace Engineering, March 1995, pp. 9-13.

Ballin, M. G. (1988). "A High Fidelity Real-Time Simulation of a Small Turboshaft Engine," NASA Technical Memorandum 100991.

Duyar, A., V. Eldem, W. Merrill, and T.-H. Guo (1994). "Fault Detection and Diagnosis in Propulsion Systems: A Fault Parameter Estimation Approach," AIAA Journal of Guidance, Control and Dynamics, 17, No. 1, pp. 104-108.

Duyar, A., Z. Gu and J. Litt (1995). "A Simplified Dynamic Model of the T700 Turboshaft Engine," Journal of the American Helicopter Society, 40, No. 4, pp. $62-70$.

Litt, J., M. Kurtkaya and A. Duyar (1995). "Sensor Fault Detection and Diagnosis of the T700 Turboshaft Engine," AlAA Journal of Guidance, Control and Dynamics, 18, No. 3, pp. 640-642.

Ogata, K. (1970). Modern Control Engineering, Prentice-Hall, Inc., Englewood Cliffs, NJ.

Prescott, W. E. and H. F. Morris (1987). T700 Training Guide, General Electric Company, Lynn, MA.

T700 (1981). Aviation Unit and Intermediate Maintenance Manual: Engine, Aircraft: Turboshaft: Models T700-GE-700, T700-GE-701, T700-GE-701C, Army TM 55-2840-248-23, Air Force T.O. 2J-T700-6. 


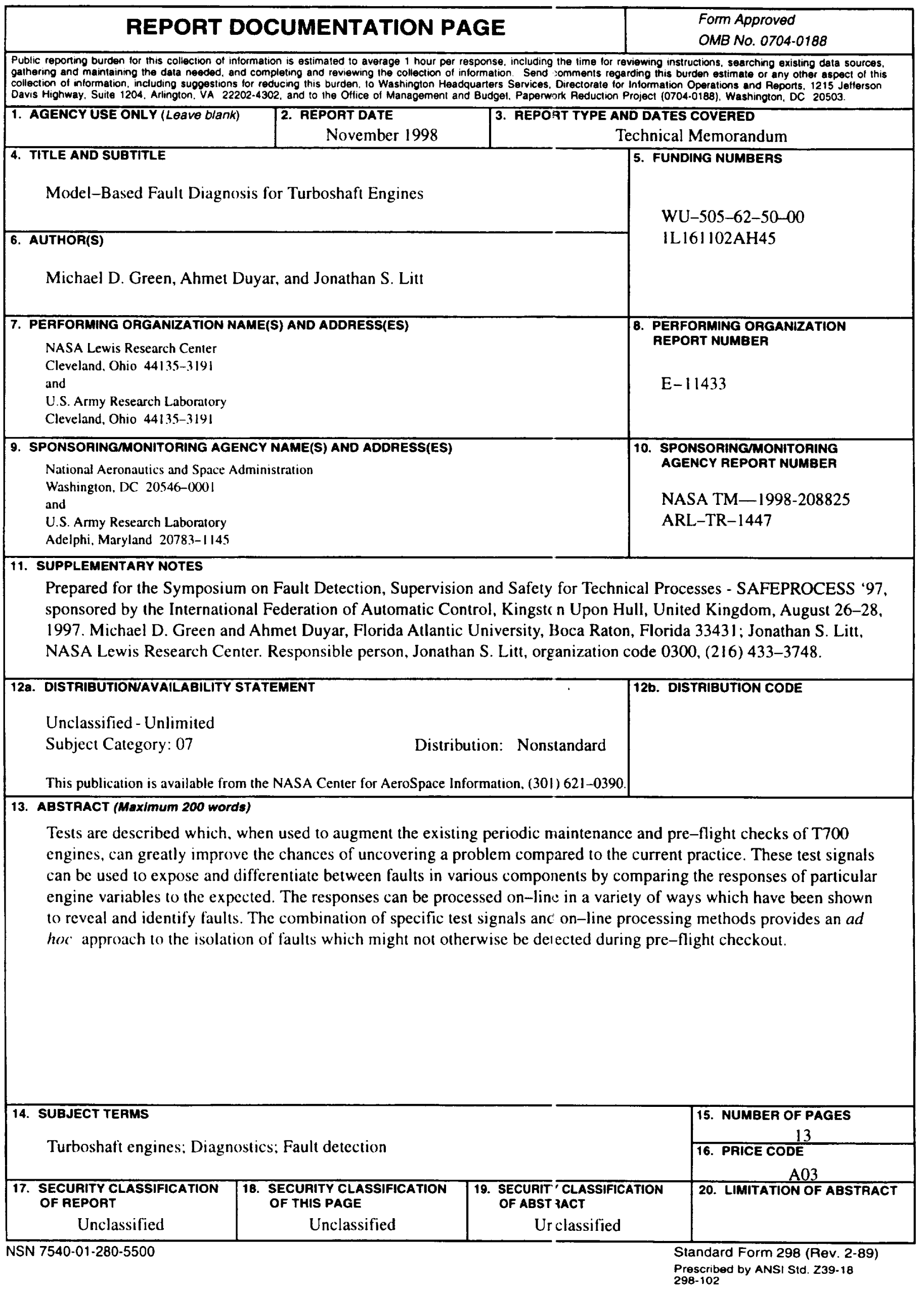

